\title{
Medicinal Electrochemistry of Halogenated and Nitrated Pterocarpanquinones
}

\author{
Thaissa L. Silva, ${ }^{a, b}$ Julio C. S. da Silva, ${ }^{a}$ Dimas J. P. Lima, ${ }^{a}$ Fabricia R. Ferreira, ${ }^{a}$ \\ Camila C. de Vasconcelos, ${ }^{a, c}$ Danyelle C. Santos, ${ }^{b}$ Chaquip D. Netto, ${ }^{d, e}$ Paulo R. R. Costa ${ }^{d}$ \\ and Marília $O$. F. Goulart ${ }^{\circ} *, a$
}

\author{
aInstituto de Química e Biotecnologia, Universidade Federal de Alagoas, 57072-970 Maceió-AL, Brazil \\ ${ }^{b}$ Núcleo de Ciências Exatas (NCEx), Universidade Federal de Alagoas, Campus de Arapiraca, \\ 57309-005 Arapiraca-AL, Brazil
}

${ }^{c}$ Centro Universitário CESMAC, R. da Harmonia, 57081-350 Maceió-AL, Brazil

${ }^{d}$ Laboratório de Química Bioorgânica, Núcleo de Pesquisas de Produtos Naturais, Centro de Ciências da Saúde, Bloco H, Universidade Federal do Rio de Janeiro, 21941-590 Rio de Janeiro-RJ, Brazil

${ }^{e}$ Laboratório de Química, Universidade Federal do Rio de Janeiro, Campus Professor Aloísio Teixeira, 27930-560 Macaé-RJ, Brazil

\begin{abstract}
Electrochemical methods are considered useful tools for simulations of biological redox reactions. The activities of quinones depend on their bioreduction. Biologically active pterocarpanquinones LQB-149 (nitroderivative), 150 and 151 (bromo and chloroderivatives, respectively) were electrochemically investigated by cyclic voltammetry, differential pulse voltammetry, and in situ UV-Vis spectroelectrochemistry, in aprotic media ( $N, N$-dimethylformamide $(\mathrm{DMF})+$ tetra- $N$-butylammonium $\left.\left(\mathrm{TBAPF}_{6}\right)\right)$. The data obtained regarding their reduction mechanisms, positive reactivity with oxygen and analysis of the electrogenerated intermediates were useful in explaining their biological outcomes. The appearance of bands at 397 and $480 \mathrm{~nm}$, for the halogenated compounds, suggests the generation of transient quinonemethides $(\mathrm{QM})$, electrophilic intermediates related to their activity. As an additional proof for the intermediacy of QM, in the redox processes, chemical reduction of LQB-150, in the presence of hexanethiol was performed and led to a thioalkylated quinone. For the nitroderivative, a broad band appeared at $432 \mathrm{~nm}$, corresponding to the generation of the nitroradical anion, giving rise to a dianion diradical, after reduction at the second wave potential. Computational data correlate well with electrochemical experiments. Homogeneous electron transfer to oxygen, yielding reactive oxygen species, the generation of electrophilic species and the radical reactivity, explain partially the mechanism of biological action.
\end{abstract}

Keywords: pterocarpanquinones, electrochemical parameters, multi-redox systems, UV-Vis spectroelectrochemistry, bioreduction

\section{Introduction}

Quinones are double-edged sword compounds. They can create a variety of hazardous effects in vivo including acute cytotoxicity, immunotoxicity, and carcinogenesis, and, in contrast, can induce cytoprotection and be relevant medicines against several diseases. ${ }^{1}$ The molecular pathways related to this bioactivity/toxicity of quinones include oxidative stress (OS) enhancement, bioreductive alkylation through the

\footnotetext{
*e-mail: mariliaofg@gmail.com
}

generation of electrophilic intermediates with consequent Michael addition of various nucleophilic endobiotics, and also through metal complexation, with similar mechanisms and sometimes increased effects. ${ }^{1,2}$ On this line, modulation of redox signaling, through specific interaction with enzymes, nuclear factors and receptors, is also, an important pathway. ${ }^{3}$ Quinones can also work as DNA intercalators, inhibitors of topoisomerases and of some enzymes of the mitochondrial electron transfer chain. ${ }^{2,3}$

Several pterocarpanquinones, hybrid quinones prepared from pterocarpans (flavonoids) and lapachol had been 
synthesized and successfully screened in terms of biological and pharmacological activities. Some of the most active were LQBs-118, 149, 150 and 151 (Figure 1). ${ }^{4}$

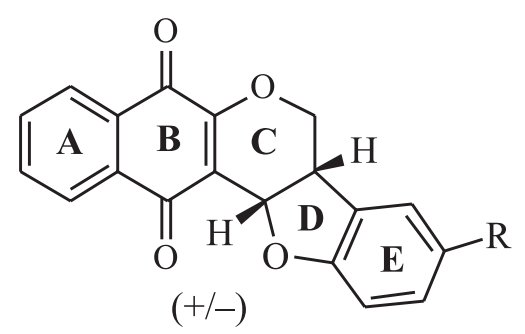

$$
\begin{aligned}
& \text { LQB-118 - } \mathrm{R}=\mathrm{H} \\
& \text { LQB-149 - } \mathrm{R}=\mathrm{NO}_{2} \\
& \text { LQB-150 - R }=\mathrm{Br} \\
& \text { LQB-151 - R }=\mathrm{Cl}
\end{aligned}
$$

Figure 1. Structures of pterocarpanquinones.

LQB-118 is a potent anticancer pterocarpanquinone, and its biological activities and mechanisms of action have been extensively reported. ${ }^{4,5}$ This pterocarpanquinone is a developing and orally active pterocarpanquinone agent that effectively induces the programmed cell death of prostate cancer cells, through quinone reduction and reactive oxygen species (ROS) generation. The inhibition of superoxide dismutase 1 (SOD1) expression enhances LQB-118 activity, presumably by impairing the cellular antioxidant response. ${ }^{6,7}$ This molecule also presents antiparasitic profile. ${ }^{5,8}$

Since reductive bioactivation could be involved in the molecular mechanism of action of these compounds, ${ }^{1,9}$ the introduction of electron withdrawing groups at the E-ring was worthy investigating, once it could stabilize the phenoxide leaving group, proposed as an intermediate product from chemical and electrochemical reduction. ${ }^{5}$

LQB-149, the nitro derivative of LQB-118, was reported to be active against human leukemic cell lines with half maximal inhibitory concentration $\left(\mathrm{IC}_{50}\right)$ against K562 of $3.48 \mu \mathrm{M}$ and of $0.40 \mu \mathrm{M}$ against HL- $60,{ }^{7}$ despite being less selective and more toxic than LQB-118, toward normal cells (PBMC), with $\mathrm{IC}_{50}$ of $8.6 \mu \mathrm{M}$. It was also assayed against HCT-8 $(8.30 \mu \mathrm{M}), \mathrm{SF}-295(8.90 \mu \mathrm{M})$ and MDA-MB435 (17.40 $\mu \mathrm{M})$, being highly selective toward HL-60. LQB-150 and LQB-151 present lower cytotoxicity: $\mathrm{IC}_{50}$ against $\mathrm{K} 562$ (5.70 and $6.77 \mu \mathrm{M}$, respectively) and HL-60 (4.87 $\mu \mathrm{M}$ for both). ${ }^{7}$

LQB-151 is a promising compound for chemotherapy to treat toxoplasmosis. It inhibited Toxoplasma gondii growth in LLCMK2 cells with $\mathrm{IC}_{50}$ value lower than $1 \mu \mathrm{M} .^{8}$ LQB-149 was also evaluated on Leishmania amazonensis in culture: promastigotes and amastigotes (the form present in the human disease), with $\mathrm{IC}_{50} 1.07$ and $1.85 \mu \mathrm{M}$, respectively. The selectivity index (SI) was calculated for amastigote form using M J7744 cells (murine macrophages) $(\mathrm{SI}=6.5)$ as reference. ${ }^{10}$

Physicochemical descriptors for LQBs-150 and $\mathbf{1 5 1}$ were also reported, suggesting that they adhere to Lipinski's rule. ${ }^{8}$

Progressive overlap of interests between electrochemistry and other areas of research, mainly biologically-based ones, allows the mastering of electrochemical methods and methodologies and approaches scientists from these different areas. ${ }^{2}$ Electrochemical methods are useful tools for simulations of biological (i.e., metabolic) redox reactions. Metabolically active sites, i.e., positions at which the drug is prone to suffer oxidation or reduction, can be rapidly elucidated through electrochemical/ computational investigations and possible metabolites can be directly identified. ${ }^{2,9}$ The majority of these intermediates are formed after oxidation of the parent compound or reduction followed by elimination, to generate electrophilic intermediates, which subsequently can react with nucleophilic groups in cellular biomacromolecules, such as lipids, proteins and DNA. ${ }^{2-4}$

LQB-118 was recently investigated by electrochemical methods, in protic and aprotic media, towards oxygen, and DNA. UV-Vis spectroelectrochemistry allowed to prove the reduction-based quinonemethide generation and along with DNA positive interaction studies, did well to predict the oxidative stress-based biological activity of the compound. ${ }^{5}$

We, herein, investigated the electrochemical behavior of biologically active halogenated and nitrated pterocarpanquinones, in aprotic media, in the absence and presence of oxygen in order to obtain data regarding their reduction mechanisms, the analysis of the stability of the electrogenerated intermediates, as well as, in the presence of thiols.

The study of compounds carrying multiple redox centers, as part of the molecular system and doubly responsible for specific properties, like in nitroquinones, deserves special attention. ${ }^{11}$

The presence of an electron-withdrawing group confers stronger oxidant properties on the quinone, but the corresponding hydroquinone or catechol is less readily oxidized. Nitroquinones have been investigated with special toxicological concern. Quinones ${ }^{1}$ and nitroaromatics ${ }^{11}$ are key pharmacophores, activated by electron transfer, coupled with prior or following chemical reactions.

Electroreduction of nitro derivatives of quinones has been described, but, in the majority of cases, without considering any relationship with pharmacological activities and any evidence of mechanistic complications. ${ }^{12}$ 
The presence of halogens in LQB-150 and $\mathbf{1 5 1}$ can also contribute to a diverse redox behavior. The electrochemistry of halogenated compounds, mainly aromatic ones (ArX), has been thoroughly investigated on several electrodes. ${ }^{13}$ For halides, bi-electronic uptake in aprotic solvents causes rupture of the $\mathrm{C}-\mathrm{X}$ bond, by either a concerted or stepwise mechanism, followed by reduction of the ensuing radical to an anion. The latter is usually protonated by residual water to the respective $\mathrm{C}-\mathrm{H}$ bond. ${ }^{13}$

As the electrophilic character of quinones has been proved to be relevant for several biological activities, ${ }^{2}$ and considering that the presence of a nitro substituent certainly makes the electron capture by the quinone moiety easier, ${ }^{12}$ this paper intends to consider the mutual influence of the redox groups on the electron transfer processes of the present pterocarpanquinones (Figure 1) and the structural properties of their electrochemically generated radical anions. The presence of halogens also contribute to the activity and to the electrochemical profile. ${ }^{13}$

In general, naturally important quinones, for instance ubiquinones, and their intermediates semi-ubiquinones, as well as reduced forms exist inside hydrophobic cell membranes. ${ }^{14}$ It is advantageous to study their electrochemical properties in trace water environment, such as aprotic organic solvents, which mimic the nonpolar environment in a living cell where the electrochemical properties differ from that observed in aqueous systems. ${ }^{2,3,14}$

\section{Experimental}

\section{Reagents and equipments}

Extra-dry $N, N$-dimethylformamide (DMF; 99.8\%) was acquired from Acros Organics, tetra$\mathrm{N}$-butylammonium $\left(\mathrm{TBAPF}_{6}\right.$ ) and tetra- $N$-butylammonium percholorate (TBAP) and the other chemicals from Sigma-Aldrich (St. Louis, USA). TBAPF $_{6}$ was purified by recrystallization from absolute ethanol $(\times 3)$, and dried at reduced pressure, at $60^{\circ} \mathrm{C}$. All the reagents were analytical grade.

Structural elucidation was performed by using 1D and 2D nuclear magnetic resonance (NMR) spectra, recorded by using a Bruker Avance 400 spectrometer $\left({ }^{1} \mathrm{H}\right.$ : 600 and ${ }^{13} \mathrm{C}$ : $150 \mathrm{MHz}$ in $\mathrm{CDCl}_{3}$ ). Cyclic voltammetry (CV) or differential pulse voltammetry (DPV) experiments were performed with a conventional undivided three-electrode cell, using an Autolab PGSTAT-30 potentiostat (Echo Chemie, Utrecht, the Netherlands), coupled to a microcomputer, interfaced by a GPES 4.9 software. UV-Vis spectra were obtained using a Hewlett Packard 8453 spectrophotometer.

\section{Synthesis}

Pterocarpanquinones LQB-149 ((7aS,12aS)-9-nitro7,7a-dihydro-5H-benzo[ $g$ ]benzofuro[3,2-c]chromene5,13(12aH)-dione), 150 ((7a, $12 \mathrm{a} S)$-9-bromo7,7a-dihydro-5H-benzo[ $g$ ]benzofuro[3,2- $c$ ] chromene5,13(12a $H$ )-dione), 151 ((7aS,12aS)-9-chloro-7,7a-dihydro$5 H$-benzo $[g]$ benzofuro[3,2- $c]$ chromene-5,13(12a $H$ )-dione) (Figure 1) were obtained from LQB-118, ${ }^{4}$ by electrophilic substitution, taking advantage of the high reactivity of E-ring for electrophilic aromatic substitution over the A-ring, which is deactivated due to the conjugation with the carbonyl groups of the quinone moiety (Figure 2).4,6 Their physicochemical parameters were herein reported. ${ }^{4,15}$ LQB-149 should be kept refrigerated and under nitrogen to avoid decomposition.

Procedure for reductive thioalkylation of LQB-150 by using hexanethiol as a nucleophile

A solution of LQB-150 (8.0 mg, $0.0209 \mathrm{mmol}$ ) in 1:1 THF/MeOH $(2.0 \mathrm{~mL})$ and Trizma buffer $(\mathrm{pH} 7.4$, $0.7 \mathrm{~mL}$ ) was degassed for $15 \mathrm{~min}$ with dry, oxygen-free argon. Sodium dithionite (ca. 1 equiv.) was added to this solution to effect hydroquinone formation, followed by

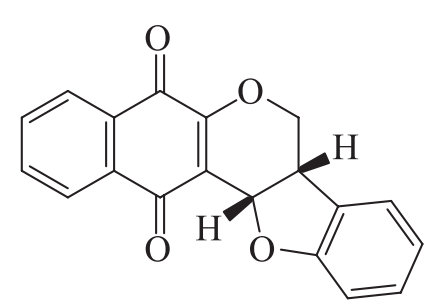

LQB 118

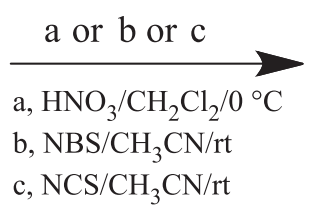

$$
\begin{aligned}
& \mathrm{R}=\mathrm{NO}_{2}=\mathbf{L Q B} 149(50 \%) \\
& \mathrm{R}=\mathrm{Br}=\text { LQB } 150(57 \%) \\
& \mathrm{R}=\mathrm{Cl}=\text { LQB } 151(55 \%)
\end{aligned}
$$

Figure 2. Synthesis of the pterocarpanquinones LQBs-149, 150 and $\mathbf{1 5 1}$ (adapted from reference 4). 
addition of a solution of hexanethiol (4 equiv.) as the nucleophile in degassed 1:1 THF/MeOH $(0.3 \mathrm{~mL}){ }^{4,5}$ The solution was stirred at room temperature (rt) under argon and the reaction was monitored periodically by using thin layer chromatography (TLC; eluent: Hex/EtOAc 7:3). Following extraction of the mixture with ethyl acetate $(2 \times 15 \mathrm{~mL})$, the organic layer was washed with water $(2 \times 10 \mathrm{~mL})$ and dried over anhydrous sodium sulfate. The solvent was removed under reduced pressure and the residue was purified by using column chromatography (silica gel, Hex/EtOAc 7.0:3.0), to afford compound $\mathbf{1}$ as a yellow solid $(6.0 \mathrm{mg}, 0.012 \mathrm{mmol}, 57 \%)$.

${ }^{1} \mathrm{H}$ NMR $\left(600 \mathrm{MHz}, \mathrm{CDCl}_{3}\right) \delta 8.11(\mathrm{dd}, J 1.2,7.2 \mathrm{~Hz}$, $1 \mathrm{H}), 8.08$ (dd, $J 1.2,7.2 \mathrm{~Hz}, 1 \mathrm{H}), 7.72$ (ddd, $J$ 1.2, 7.2, $7.2 \mathrm{~Hz}, 1 \mathrm{H}), 7.69$ (ddd, J 1.2, 7.2, 7.2 Hz, 1H), 7.32 (d, J $2.4 \mathrm{~Hz}, 1 \mathrm{H}), 7.20$ (dd, J 2.4, $8.4 \mathrm{~Hz}, 1 \mathrm{H}), 6.67$ (d, $J 8.4 \mathrm{~Hz}, 1 \mathrm{H}), 4.93$ (dd, J 3.3, $12 \mathrm{~Hz}, 1 \mathrm{H}), 4.88$ (dt, J 1.8, $12 \mathrm{~Hz}, 1 \mathrm{H}), 4.32$ (s, 1H), 3.01-2.97 (m, 1H), 2.91-2.87 (m, $1 \mathrm{H}), 1.75-1.67(\mathrm{~m}, 2 \mathrm{H}), 1.41-1.36(\mathrm{~m}, 2 \mathrm{H}), 1.29-1.25(\mathrm{~m}$, $6 \mathrm{H}), 0.87$ (t, $J 7.2 \mathrm{~Hz}, 3 \mathrm{H}) ;{ }^{13} \mathrm{C} \mathrm{NMR}\left(150 \mathrm{MHz}, \mathrm{CDCl}_{3}\right)$ $\delta$ 183.0, 179.1, 154.1, 152.2, 134.2, 133.3, 132.2, 131.4, $130.9,129.7,128.3,126.6,126.5,120.1,116.9,113.3,66.7$, $37.1,37.0,33.7,31.4,29.8,28.7,22.6,14.0$.

\section{Electrochemical studies}

The electrochemical studies of halogenated and nitropterocarpanquinones, on glassy carbon electrode (GCE), were performed to evaluate their electrochemical behaviors, in aprotic medium, prior to the electrochemical studies with oxygen.

The working electrode was a GCE $(\mathrm{d}=3 \mathrm{~mm})$, the counter electrode was a $\mathrm{Pt}$ wire, and the reference electrode was an $\mathrm{Ag}|\mathrm{AgCl}| \mathrm{Cl}^{-}$(saturated). Pt electrode $(\mathrm{d}=1.6 \mathrm{~mm})$ was also used as a working electrode. All electrodes were contained in a one-compartment electrochemical cell with a volumetric capacity of $5 \mathrm{~mL}$. GCE was cleaned up by polishing with alumina on a polishing felt (BAS polishing kit). In CV experiments, the scan rate varied from 10 to $500 \mathrm{mV} \mathrm{s}^{-1}$. For DPV measurements, the pulse amplitude was $50 \mathrm{mV}$, the pulse width was $70 \mathrm{~ms}$ and the scan rate was $5 \mathrm{mV} \mathrm{s}^{-1}$. All experiments were performed at room temperature $\left(25 \pm 1^{\circ} \mathrm{C}\right)$. Except when reported, all the $\mathrm{CVs}$ were displayed at scan rates of $100 \mathrm{mV} \mathrm{s}^{-1}$.

Electrochemical reduction was performed in aprotic media $\left(0.1 \mathrm{~mol} \mathrm{~L}^{-1} \mathrm{DMF}+\mathrm{TBAPF}_{6}\right)$, at room temperature $\left(25 \pm 2{ }^{\circ} \mathrm{C}\right)$. Each compound $\left(1 \times 10^{-3} \mathrm{~mol} \mathrm{~L}^{-1}\right)$ was added to the supporting electrolyte, and the solution was deoxygenated with argon, before the CV measurements. The most representative potential range was from 0 to $-2.2 \mathrm{~V}$ vs. $\mathrm{Ag}|\mathrm{AgCl}| \mathrm{Cl}^{-}$(sat.).
To investigate the reactivity of LQB-149, LQB-150 and LQB-151 toward oxygen, electrochemical reduction in aprotic media $\left(0.1 \mathrm{~mol} \mathrm{~L}^{-1} \mathrm{DMF}+\mathrm{TBAP}\right)$ was performed in the presence and absence of oxygen. Oxygen was bubbled into the cell and its concentration monitored by an oxygen meter (Digimed DM-4). Cyclic voltammograms were recorded at different oxygen concentrations. The parameters analyzed were anodic shifts of the potential of the first reduction wave (EpIc) and current increase at the same peak (IpIc) or decrease of the correspondent anodic peak (IpIa). ${ }^{16}$

Spectroelectrochemical experiments were performed on a thin-layer quartz electrochemical cell (path length $1 \mathrm{~mm}$, BASi) with a three-electrode arrangement consisting of an optically transparent platinum minigrid as working electrode, a Pt wire as counter electrode and $\mathrm{Ag}|\mathrm{AgCl}| \mathrm{Cl}^{-}$as reference. The cell was paired to the already described potentiostat and the spectra were obtained using a Hewlett Packard 8453 spectrophotometer. ${ }^{5,16}$ Measurements were carried out on deoxygenated solutions in $0.1 \mathrm{~mol} \mathrm{~L}-1 \mathrm{DMF}+\mathrm{TBAPF}_{6}$, at room temperature. The concentrations of $\mathbf{L Q B - 1 5 0}$ and LQB-151 were $1.0 \times 10^{-3} \mathrm{~mol} \mathrm{~L}^{-1}$. The applied potentials were -0.6 and $-1.1 \mathrm{~V}$.

In the case of LQB-149, similar conditions were used, except the applied potentials, which were $-0.5,-0.6$ and $-0.9 \mathrm{~V}$ vs. $\mathrm{Ag} / \mathrm{AgCl}, \mathrm{Cl}^{-}$.

\section{Computational details}

Full unconstrained geometry optimization and frequency calculations were carried out using the hybrid GGA B3LYP exchange-correlation functional. ${ }^{17}$ The triple zeta valence polarization (TZVP) basis set was used for describing $\mathrm{H}, \mathrm{C}, \mathrm{O}, \mathrm{N}, \mathrm{Cl}$ and $\mathrm{Br}$ atoms. ${ }^{18}$ The electronic spectra of all systems investigated were evaluated according to the time-dependent density functional theory (TD-DFT) formalism, using the 6 B97DX exchange-functional, ${ }^{19,20}$ and TZVP basis set for all atoms. Solvent effects on electronic spectra calculations were treated using the linear response theory coupled with polarizable continuum model (LR-PCM), ${ }^{21}$ considering a dielectric constant equal to 37.219. All calculations were carried out using Gaussian09 program. $^{22}$

\section{Results and Discussion}

\section{Electrochemistry}

DMF was chosen as an aprotic organic solvent for electrochemical studies, because it can mimic the nonpolar environment in the cell, where lipid peroxidation, one of the causes of membrane fragmentation, normally occurs. ${ }^{23}$ 
Non-aqueous solvents provide better models of a membrane environment, in which peroxidation processes take place, because both the superoxide radical anion and its conjugated acid, the hydroperoxyl radical, are unstable in water and other protic solvents, owing to their fast disproportionation. ${ }^{5,16}$ Additionally, in these conditions, single electron transfer occurs, generating the active semiquinone. ${ }^{2}$

As LQB-118, its halogenated derivatives, LQB-150 and 151, and nitrated one, LQB-149, have a paranaphthoquinone moiety, coupled to halogenated and nitrated aromatic rings, through non-conjugated pterocarpane-based spacers (Figure 1).

For LQB-150 and 151, the electrochemical profiles are complex, with at least 4 cathodic waves and a small, ill-defined shoulder (I'c), between waves Ic and IIc (Figures 3a-3d, Table 1). As shown before, ${ }^{5}$ the first wave corresponds to the formation of the semiquinone, while the second is related to the dianion of the generated hydroquinones. Additional waves refer to transient electrogenerated intermediates. ${ }^{5}$ Four anodic waves are present, which correspond to reduction peaks Ic (peak Ia), IIc (IIa and II'a) and IVc (IIIa) (Table 1).

As the electrochemical behaviors of LQB-150 and 151 are very similar, detailed description will be provided for LQB-150 (Figure 3, Table 1).

The first redox pair $(\mathrm{Ic} / \mathrm{Ia})$ is diffusion-controlled $\left(\operatorname{Ip}_{\text {Ic }} v s . v^{1 / 2}\right)$ (Figure 3c), quasi-reversible, with $\Delta \mathrm{Ep}=76 \mathrm{mV}$, EpIc does not modify with scan rate, Ipa/Ipc ca. 1 (Figure 3a, after reversion of potential at ca. $-0.6 \mathrm{~V})$, with the generation of a stable semiquinone. The second reduction process (IIc/IIa and II'a), corresponding to the formation of the hydroquinone dianion, is quite different from the first one, with a very low intensity anodic counterpart IIa. It also does not correspond to the usual behavior of quinones. Successive scans (Figure 3b) show a similar pattern as the first scan, with a slight increase of peak I'c. Upon potential inversion (Figure 3a), its correspondence to the peak assigned as II'a is observed. This behavior comes from its higher basicity, and cleavage of the pterocarpane moiety, originating a phenolate, which oxidation occurs at II'a. This behavior was reported recently for the standard compound (LQB-118), through electrochemical reduction, ${ }^{5}$ similarly to the homogenous chemical reaction.

It is well-known that electron-withdrawing groups, in conjugation to the electroactive group, facilitates its reduction, with an anodic shift in its reduction potential. ${ }^{11}$ That is the case for LQB-149, with two electroactive groups: the quinone and the aromatic nitro group. The comparison between Figures 3a, 3d and 3e reveals different redox profiles.
For LQB-149, it is evident the presence of five reduction waves (Ic-Vc) and four ill-defined oxidation ones (Figure $3 \mathrm{e})$. The first wave $(\mathrm{Ic}=-0.579 \mathrm{~V})$ is diffusionalcontrolled $\left(\operatorname{Ip}_{\text {Ic }} v s . v^{1 / 2}\right)$, similar to the others, with a slightly more positive potential, once there is no conjugation between the redox groups. It represents a quasi-reversible process, $\Delta \mathrm{Ep}=89 \mathrm{mV}$, EpIc does not modify with scan rate. The second wave is broad (IIc $=-0.787 \mathrm{~V}$ ), presents an anodic counterpart, and is related to the reduction of the nitro group, probably generating a biradical-dianion, reported before for ortho-quinones substituted with nonconjugated nitroanilines. ${ }^{12}$ Waves IIIc and IVc are similar to the other compounds and the last reduction wave, Vc, irreversible in terms of the nature of electron transfer $(\mathrm{Vc}$ $=-2.116 \mathrm{~V}$ ), with a higher current intensity, is related to the further reduction of the nitro radical anion. ${ }^{11,12}$

Further redox information, under the same condition, can be obtained through the use of DPV, once it is a more sensitive electrochemical technique.

The comparison of redox profiles is better visualized in Figure 4, where the three compounds are compared with the unsubstituted one, LQB-118. ${ }^{5}$ Due to the difference in scan rate, DPV can be slightly different from CV.

As the standard compound (LQB-118), the two halogenated compounds had shown 4 main waves, at similar potentials. The presence of shoulders between Ic and IIc (Figure 4 ) occurs, when a $\mathrm{C}-\mathrm{X}(\mathrm{X}=$ halogen) bonding is present and the reason of their presence is still uncertain.

LQB-149 is clearly different, represented by five main waves, the last one, very broad. As already shown by $\mathrm{CV}$, waves Ic and IIc correspond to the sequential monoelectronic reduction of the quinone and nitro functionalities, and the others related to the reduction of the dianion diradical, to the tri-anion-radical, which suffers cleavage, as evidenced for the other compounds. Wave Vc (broad), as shown before in $\mathrm{CV}$, is related to an extended reduction of the nitro radical anion.

In situ UV-Vis spectroelectrochemistry in aprotic medium

This technique is useful for giving detailed structural information about the compounds obtained from heterogeneous electron transfer reactions. ${ }^{5,14}$ The changes in radical intermediates (semiquinones), in $0.1 \mathrm{~mol} \mathrm{~L}^{-1} \mathrm{DMF}+\mathrm{TBABF}_{6}$, originated at the first reduction potential, and final reduced species, can be monitored by electronic transitions, using in situ UV-Vis spectroelectrochemical experiments, in a kinetic mode for collecting spectra. Table 1 lists all the reduction potentials (in $\mathrm{V}$ ) and data on UV-Vis (nm), before and after reduction. 

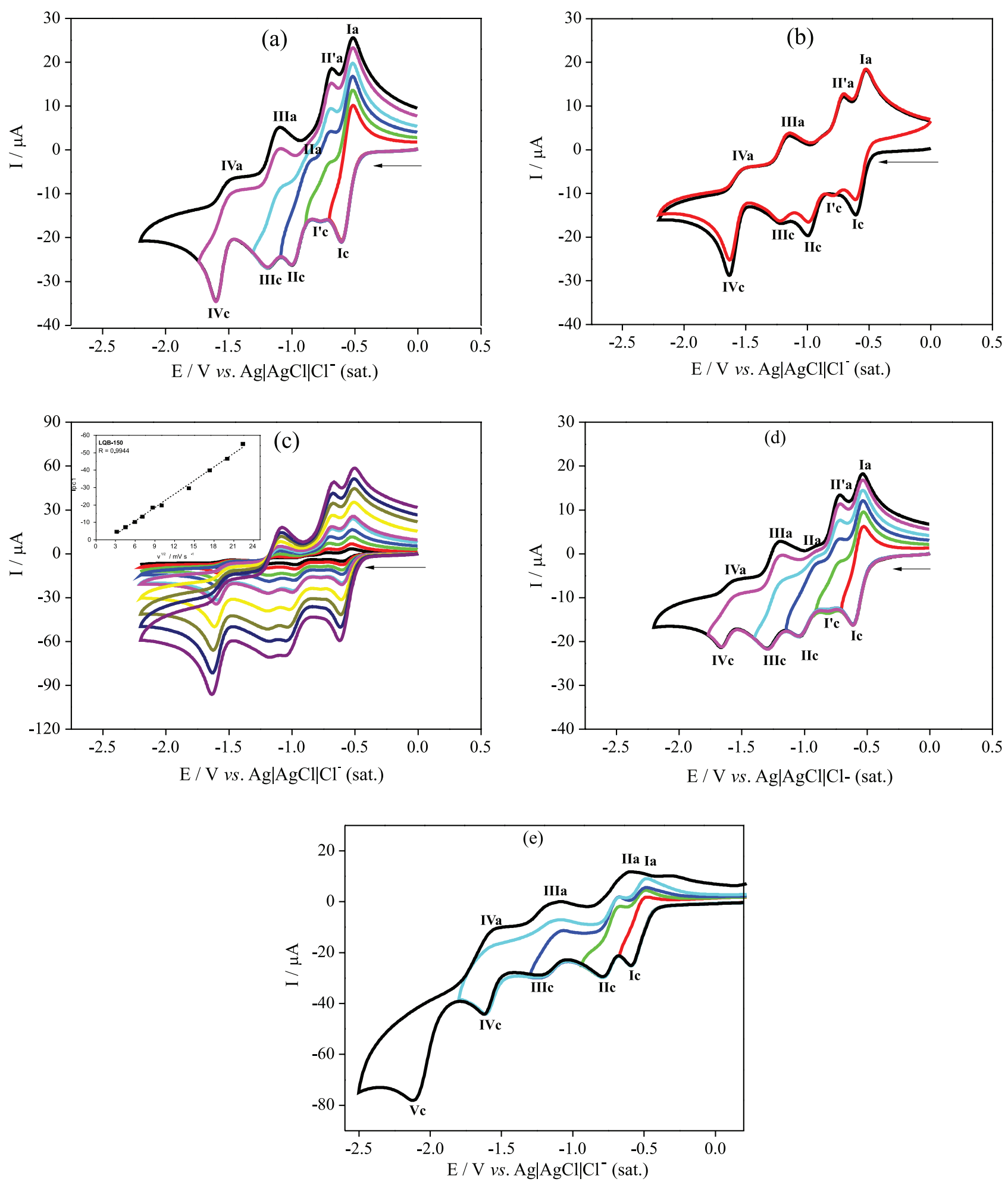

Figure 3. Cyclic voltammetry $(\mathrm{CV})$ of compounds $\left(1 \mathrm{mmol} \mathrm{L}^{-1}\right)$ in $\mathrm{DMF}+\mathrm{TBAPF}_{6}\left(0.1 \mathrm{~mol} \mathrm{~L}^{-1}\right)$, glassy carbon electrode, $v s$. Ag/AgCl, $\mathrm{Cl}^{-}, \mathrm{cathodic}$ direction, $v=100 \mathrm{mV} \mathrm{s}^{-1}$. (a) LQB-150, different inversion potentials; (b) LQB-150, successive CVs; black line: scan 1, red line: scan 2; (c) LQB-150, CVs at different scan rates of 20,40,60,80,100,150, and $200 \mathrm{mV} \mathrm{s}^{-1}$. The inset shows the linear increasing of the redox peak current depends on increasing the square root of the scan rate; (d) LQB-151, different inversion potentials; (e) LQB-149, different inversion potentials.

As aforementioned, there is similarity in electrochemical behavior for the standard compound, LQB-118, already reported, ${ }^{5}$ and its halogenated derivatives. Before reduction,
LQB-150 and 151 exhibit two main waves, related to $\pi-\pi^{*}$ and $\mathrm{n}-\pi^{*}$ transitions, at 280 and $330 \mathrm{~nm}$ (Table 1, Figure 5). During the cathodic scan, in the potential range of 0 up 
Table 1. Major electrochemical parameters $(V)$ in CV and DPV of LQB-149 $\left(c=1 \mathrm{mmol} \mathrm{L}^{-1}\right), \mathbf{L Q B}-\mathbf{1 5 0}$ and $\mathbf{L Q B}-\mathbf{1 5 1}$, in DMF $+\mathrm{TBAPF}_{6}, 0.1 \mathrm{~mol} \mathrm{~L}^{-1}$, $v=100 \mathrm{mV} \mathrm{s}^{-1}$

\begin{tabular}{|c|c|c|c|c|c|c|c|c|c|c|c|c|c|c|c|c|c|c|c|c|}
\hline \multirow{3}{*}{$\begin{array}{l}\text { Compound } \\
\text { LQB-118 }\end{array}$} & \multicolumn{10}{|c|}{ Cyclic voltammetry (CV) } & \multicolumn{5}{|c|}{ Differential pulse voltammetry (DPV) } & \multicolumn{5}{|c|}{ UV-visible } \\
\hline & \multirow{2}{*}{$\begin{array}{c}\mathrm{Ep}_{\mathrm{rc}} / \\
\mathrm{v}\end{array}$} & \multirow{2}{*}{$\begin{array}{c}\mathrm{Ep}_{\mathrm{IIV}} \mathrm{l} \\
\mathrm{V}\end{array}$} & \multirow{2}{*}{$\begin{array}{c}\mathrm{Ep}_{\mathrm{III}} / \\
\mathrm{V}\end{array}$} & \multirow{2}{*}{$\begin{array}{c}\mathrm{Ep}_{\mathrm{Ivc}} / \\
\mathrm{v} \\
-1.688\end{array}$} & \multirow{2}{*}{$\begin{array}{c}\mathrm{Ep}_{\mathrm{v}_{\mathrm{v}}} / \\
\mathrm{v}\end{array}$} & \multirow{2}{*}{$\begin{array}{c}\mathrm{Ep}_{\mathrm{ia}} / \\
\mathrm{V} \\
-0.548\end{array}$} & \multirow{2}{*}{$\begin{array}{c}\mathrm{Ep}_{\mathrm{Ir} \mathrm{a}} \mathrm{a} \\
\mathrm{V} \\
-0.757\end{array}$} & \multirow{2}{*}{$\begin{array}{c}\mathrm{Ep}_{\mathrm{III}} / \\
\mathrm{V} \\
-0.992\end{array}$} & \multirow{2}{*}{$\begin{array}{c}\mathrm{Ep}_{\mathrm{III}} / \\
\mathrm{V}\end{array}$} & \multirow{2}{*}{$\begin{array}{c}\mathrm{Ep}_{\mathrm{IVa}_{\mathrm{V}}} / \\
\mathrm{V}\end{array}$} & \multirow{2}{*}{$\begin{array}{c}\mathrm{Ep}_{\mathrm{Ic}} \text { / } \\
\mathrm{V}\end{array}$} & \multirow{2}{*}{$\begin{array}{c}\mathrm{Ep}_{\mathrm{IIV}} / \\
\mathrm{V} \\
-1.036\end{array}$} & \multirow{2}{*}{$\begin{array}{c}\mathrm{Ep}_{\mathrm{Wll}} \mathrm{c} \\
\mathrm{v} \\
-1.251\end{array}$} & \multirow{2}{*}{$\begin{array}{c}\mathrm{Ep}_{\mathrm{IVc}} / \\
\mathrm{V} \\
-1.615\end{array}$} & \multirow{2}{*}{$\begin{array}{c}\mathrm{Ep}_{\mathrm{ve}_{\mathrm{c}}} / \\
\mathrm{V}\end{array}$} & \multirow{2}{*}{$\begin{array}{c}\lambda_{\text {initial }} / \\
\mathrm{nm}\end{array}$} & \multicolumn{4}{|c|}{$\begin{array}{l}\text { New bands after reduction } \\
(\lambda) / \mathrm{nm}\end{array}$} \\
\hline & & & & & & & & & & & & & & & & & 331 & 400 & 470 & 600 \\
\hline LQB-149 & -0.579 & -0.787 & -1.233 & -1.608 & -2.116 & -0.490 & - & -0.607 & -1.125 & - & -0.532 & -0.721 & -1.146 & -1.649 & -1.952 & 279 & 326 & 432 & - & - \\
\hline LQB-150 & -0.592 & -0.792 & -0.996 & -1.194 & -1.595 & -0.516 & - & -0.684 & - & - & -0.547 & -0.923 & -1.216 & -1.584 & - & - & - & - & - & - \\
\hline LQB-151 & -0.602 & -0.810 & -1.043 & -1.294 & -1.668 & -0.532 & - & -0.717 & - & - & -0.542 & -0.899 & -1.133 & -1.542 & - & 280 & 330 & 397 & 480 & 607 \\
\hline
\end{tabular}

$\mathrm{Ep}_{\mathrm{Ic}}$ : potential of the cathodic wave Ic; $\mathrm{Ep}_{\mathrm{IIc}}$ : potential of the cathodic wave IIc; $\mathrm{Ep}_{\mathrm{IIIc}}$ : potential of the cathodic wave IIIc; $\mathrm{Ep}_{\mathrm{IV} \mathrm{v}}$ : potential of the cathodic wave IVc; $\mathrm{Ep}_{\mathrm{Vc}}$ : potential of the cathodic wave Vc; $\mathrm{Ep}_{\mathrm{Ia}}$ : potential of the anodic wave Ia; $\mathrm{Ep}_{\mathrm{II}}$ : potential of anodic wave II'a; $\mathrm{Ep}_{\mathrm{IIa}}$ : potential of anodic wave IIa; $\mathrm{Ep}_{\mathrm{III}}$ : potential of anodic wave IIIa; $\mathrm{Ep}_{\mathrm{IVa}}$ : potential of anodic wave IVa.

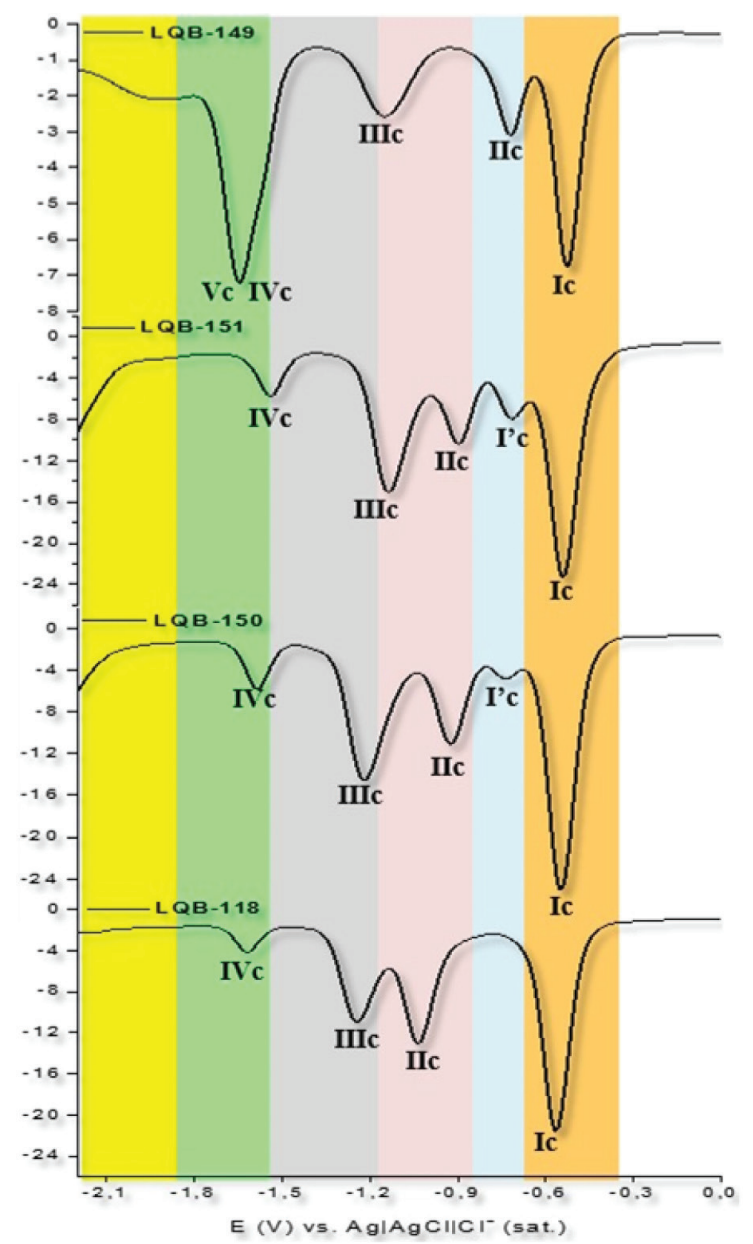

Figure 4. Differential pulse voltammograms for the studied compounds, LQB-149, 150, 151, together with LQB-118 $\left(c=1 \mathrm{mmol} \mathrm{L}^{-1}\right)$, in $\mathrm{DMF}+\mathrm{TBAPF}_{6}\left(0.1 \mathrm{~mol} \mathrm{~L}^{-1}\right)$, glassy carbon electrode, $v=5 \mathrm{mV} \mathrm{s}^{-1}$.

to $-1.5 \mathrm{~V}$, significant modifications in the UV-Vis spectra occurred, indicative of structural changes. As shown in Figure 5, the band at $280 \mathrm{~nm}$ is blue-shifted (from 280 to $274 \mathrm{~nm}$ ). New bands have appeared at 397 and $480 \mathrm{~nm}$, followed by a low-intensity one at $607 \mathrm{~nm}$ (Table 1). The last bands were assigned to the absorption of the electrogenerated quinonemethide $(\mathrm{QM})$. $^{5,24-27}$

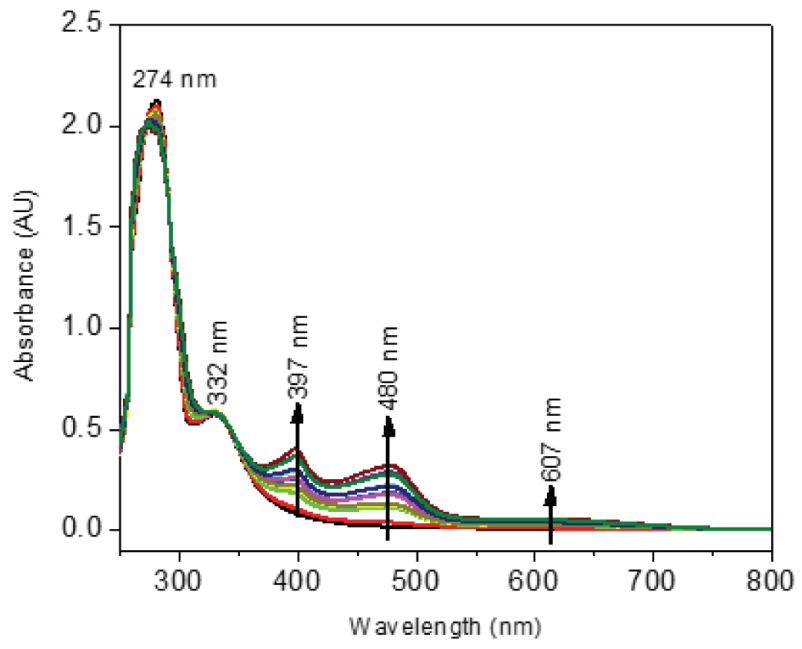

Figure 5. In situ UV-Vis spectra in $0.1 \mathrm{~mol} \mathrm{~L}^{-1} \mathrm{DMF}+\mathrm{TBAPF}_{6}$, obtained in an optically transparent electrochemical cell, optical path of $1 \mathrm{~mm}$ of LQB-151 $\left(c=1.0 \mathrm{mmol} \mathrm{L}^{-1}\right)$, Pt electrode. UV-Vis spectrum obtained after applying the second wave potential, during $240 \mathrm{~s}$. Initial waves at 280 and $330 \mathrm{~nm}$ are from non-reduced LQB-151.

To get additional evidences for the occurrence of the putative quinonemethide, derived from LQB-151, the reduction was held, into the UV cell, in the presence of electrochemically/UV-Vis transparent hexanethiol (Figure 6). A potential of $-1.1 \mathrm{~V}$, relative to the second reduction wave, was applied. For the first $180 \mathrm{~s}$, the absorption bands of the QM (Figure 6, pink line) were evidenced. Soon after this contact time, a significant decrease on absorbance of these bands were observed (Figure 6, green line at $600 \mathrm{~s}$ ), indicative of the QM capture, through thioalkylation, as confirmed as follows and similarly to reported behavior of LQB-118, by homogeneous chemical reaction. ${ }^{5}$

The spectroelectrochemistry of LQB-150 was also held and had shown similar results as LQB-151 (figure not shown). In order to get a more definite proof of the QM capture, envisaged in the spectroelectrochemical experiment (Figure 6), a chemical reduction by sodium dithionite was performed in the presence of hexanethiol 


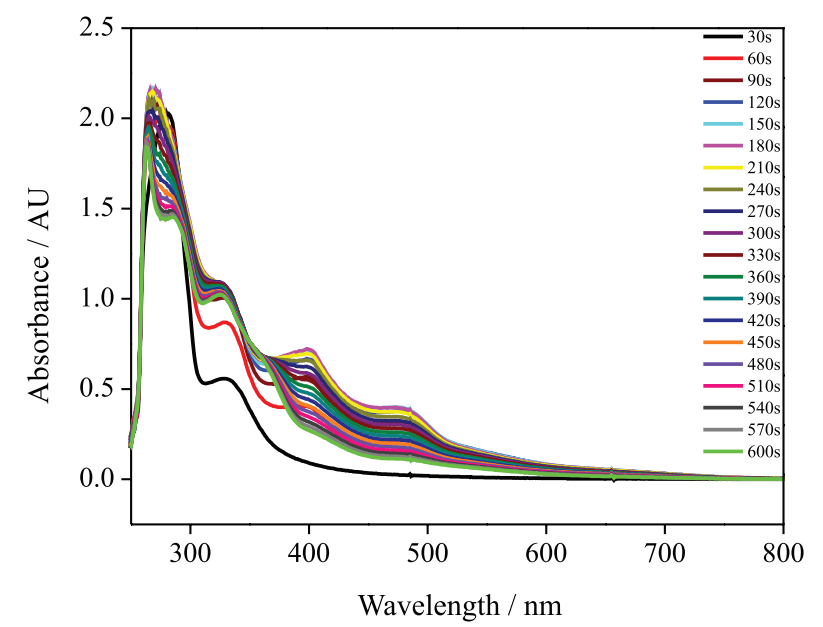

Figure 6. Successive UV-Vis spectra of LQB-151 $\left(c=1.0 \mathrm{mmol} \mathrm{L}^{-1}\right)$, in $0.1 \mathrm{~mol} \mathrm{~L}^{-1} \mathrm{DMF}+\mathrm{TBAPF}_{6}$, in a quartz cell, optical path of $1 \mathrm{~mm}$, applying a potential of $-1.1 \mathrm{~V}$, during 30 up to $600 \mathrm{~s}$, in the presence of UV-Vis transparent hexanethiol.
(Figure 7), using LQB-150. A novel thiosubstituted compound 1 was obtained and characterized by ${ }^{1} \mathrm{H}$ and ${ }^{13} \mathrm{C}$ NMR (see Figures S2 and S3, Supplementary Information (SI) section).

Combined data allowed to build the following scheme for the electrochemical reduction of LQB-150 (Figure 8).

For LQB-149, the spectroelectrochemical experiments were performed under the same conditions $\left(\mathrm{DMF}+\mathrm{TBABF}_{6}, 0.1 \mathrm{~mol} \mathrm{~L}^{-1}\right)$. The UV-Vis spectra showed a different pattern when compared with LQB-151 and reported LQB-118. ${ }^{5}$

Before reduction, LQB-149 (nitroderivative) was characterized by transitions $\pi-\pi^{*}$ and $n-\pi^{*}$ at 279 and $326 \mathrm{~nm}$ (Table 1, Figure 9, red line). After applying the potential of $-0.9 \mathrm{~V}$, for 240 or $500 \mathrm{~s}$, the absorbance of the last bands decreased, with the appearance of a new one, at $432 \mathrm{~nm}$ (Figure 9). It is useful to remark that the absorption<smiles>CCCCCCS</smiles><smiles>CCCCCCSC1C2=C(OCC1c1cc(Br)ccc1O)C(=O)c1ccccc1C2=O</smiles>

Figure 7. Reductive thioalkylation of LQB-150.

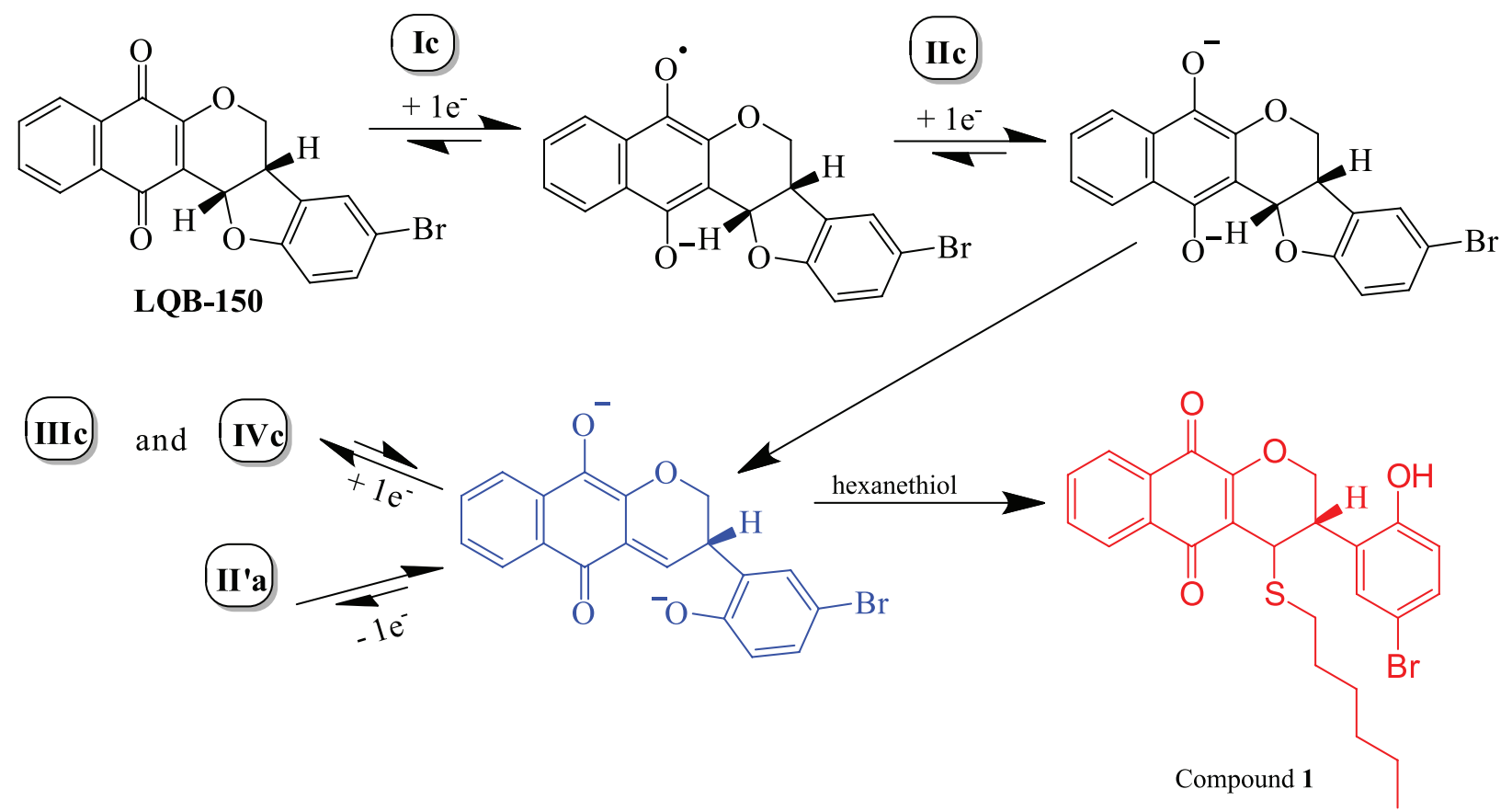

Figure 8. Possible reduction mechanism for the reduction of LQB-150. Protonation steps were not included. In blue, the generated quinonemethide (QM), able to react with hexanethiol, leading to the new compound $\mathbf{1}$ (red). 
bands, associated to QM, were not present, suggesting a different reduction outcome. For LQB-149, there is, at the second potential wave, the reduction of the nitro group, giving the nitro radical anion (Figure 10).

The presence of the radical anion nitro was earlier

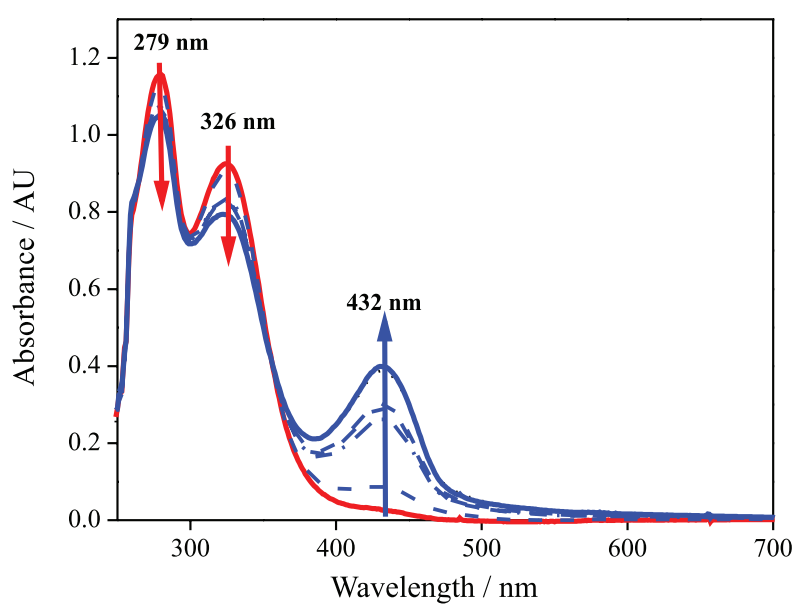

Figure 9. In situ $\mathrm{UV}$-Vis spectra in $0.1 \mathrm{~mol} \mathrm{~L}^{-1} \mathrm{DMF}+\mathrm{TBAPF}_{6}$, obtained in an optically transparent electrochemical cell, optical path of $1 \mathrm{~mm}$ of LQB-149 $\left(c=1.0 \mathrm{mmol} \mathrm{L}^{-1}\right)$, Pt electrode. The initial spectrum is represented by two bands at 279 and $326 \mathrm{~nm}$ (curve in red), followed by UV-Vis spectrum obtained after applying close to the second wave potential $(-0.9 \mathrm{~V})$, during $240 \mathrm{~s}$ (curve in blue). observed for polinitrocalix[4]arenes and several other nitroaromatics. ${ }^{28}$ A new absorption UV-Vis band with a maximum at $451 \mathrm{~nm}$ is formed, as a consequence of reductive electrolysis monitored by coulometry, under the same conditions $\left(\mathrm{DMF}+\mathrm{Bu}_{4} \mathrm{NPF}_{6}\right){ }^{28}$

Based on the above facts, the reduction mechanism for LQB-149 was proposed as shown in Figure 10.

\section{Electrochemical studies in the presence of oxygen}

As already reported, one of the proposed molecular mechanism of action for pterocarpanquinones is the bioreduction, which in presence of oxygen, leads to the release of ROS, assigned as electron transfer/oxidative stress (ET/OS), ${ }^{1,2,5}$ definetely recognized as an important mechanism against cancer cells and parasites. The interaction of quinones with oxygen, including from LQB-118, ${ }^{5}$ have already been reported and presented some positive trends, revealed when electroactivity was compared with biological parameters. ${ }^{2,5}$

Based on the relevant role of redox cycling of quinones and nitroquinones, in the presence of oxygen, LQB-149, LQB-150 and $\mathbf{1 5 1}$ were also analyzed towards oxygen, in aprotic media, as explained before. LQB-118 was included for comparison purposes. LQB-151 was chosen for a

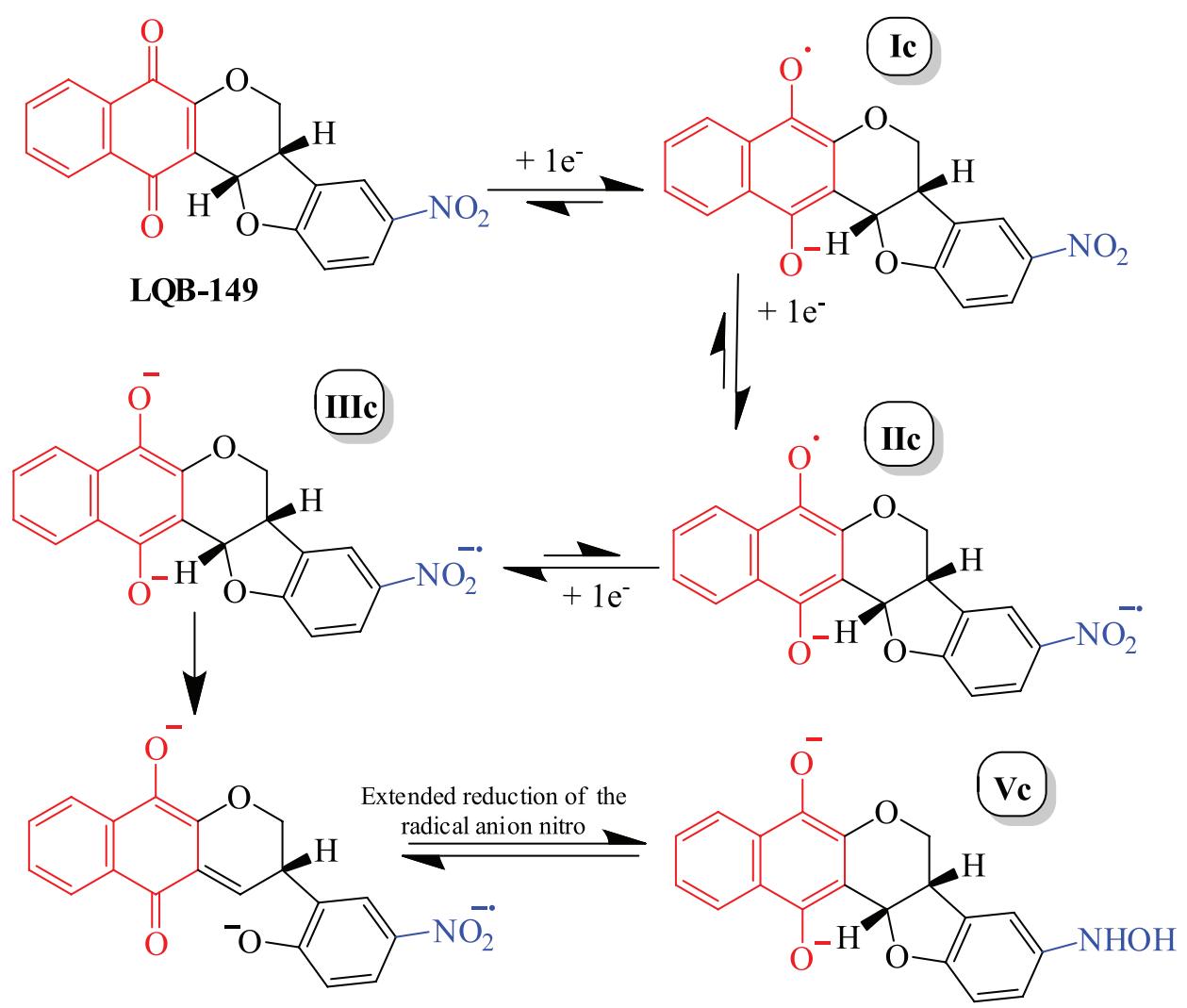

Figure 10. Proposed mechanism for LQB-149. In red, reduction of the quinone moiety, and in blue, the reduction of the nitro group. The protonation steps were not included. 
more complete study, as shown in Figure 10. Oxygen is electroactive (Figure 11, in blue). Upon addition of oxygen, in the electrochemical cell, in the presence of LQB-151 ( $\mathrm{CV}$ in black), there is a slight anodic shift of the first reduction potential $\left(\mathrm{Ep}_{\mathrm{Ic}}\right)$ and the increase of respective current (IpIc), diagnostic features for oxygen interaction ( $\mathrm{CV}$ in red). The addition of oxygen also leads to the constant regeneration of the initial quinone, resulting in the disappearance of the sequential reduction peaks $(\mathrm{CV}$ in red). It is also useful to note that the reaction with $\mathrm{O}_{2}$ is reversible and does not cause structural modification. This was proved by deaeration with nitrogen and recovery of the original redox profile of LQB-151 (figure not shown).

The reactivities of these 3 quinones toward oxygen are displayed in Figure 12, where the diagnostic figures appeared, represented by an increase of the current of the first cathodic wave and decrease of the corresponding anodic one. The apparent rate constant, obtained as already shown, ${ }^{5,17}$ are similar, with a lower value for LQB-149 (Figure 12): ${ }^{17}$

LQB-118 $\left(0.17 \mathrm{~s}^{-1}\right) \sim$ LQB-150 $\left(0.13 \mathrm{~s}^{-1}\right)=$ LQB-151 $\left(0.13 \mathrm{~s}^{-1}\right)>$ LQB-149 $\left(0.08 \mathrm{~s}^{-1}\right)$

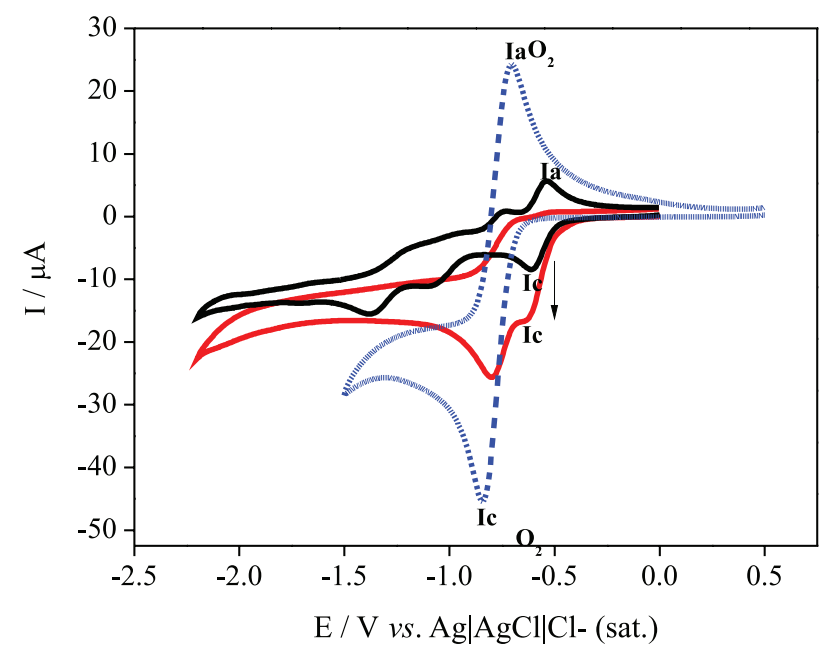

Figure 11. Cyclic voltammograms of LQB-151, in DMF + TBAP $\left(0.1 \mathrm{~mol} \mathrm{~L}^{-1}\right), \mathrm{GCE}$, in absence of oxygen (black) and in the presence of oxygen (red), $v=50 \mathrm{mV} \mathrm{s}^{-1}$. In blue, oxygen in $\mathrm{DMF}+\mathrm{TBAPF}_{6}$.

Present results suggest the generation of ROS, important and proved mechanism for the cytotoxic and antiparasitic activities of these compounds. ${ }^{5,16}$

\section{Computational studies}

DFT and TD-DFT calculations were carried out in order to get additional information regarding the nature of the UV-Vis spectra of the compounds studied (LQB-118,
LQB-149, LQB-150 and LQB-151). Figure 13 displays the UV-Vis spectra calculated at $\omega B 97 D X / T Z V P(L R-P C M)$ level of theory.

According to current spectroelectrochemical results herein presented (Table 1, Figures 5, 6 and 9), the UV-Vis spectra of LQB-118, LQB-149, LQB-150 and LQB-151 before reduction are characterized by two well-defined bands, one at 276-280 $\mathrm{nm}$ and another between $326-331 \mathrm{~nm}$. The results presented in Figure 13 shows that the results obtained at $\omega B$ 97DX/TZVP(LR-PCM) level of theory are in good agreement with these experimental values. In relation to LQB-118 (curve in black), for instance, the calculated values of ca. $265.0 \mathrm{~nm}$ for the first band and ca. $300.0 \mathrm{~nm}$ for the second one is in close agreement with values of 276.0 and $331.0 \mathrm{~nm}$ observed experimentally. Similar agreement was also obtained if we compare the calculated values (curve in red) of ca. 285.0 and $314 \mathrm{~nm}$ with experimental values of 279 and $326 \mathrm{~nm}$ determined for LQB-149. For LQB-150 (curve in blue), the calculated values of the first and second absorption bands were ca. 284.0 and $317.0 \mathrm{~nm}$. The theoretical results are also in line with the slight bathochromic effect observed experimentally for the first absorption band, when one of the aromatic rings of LQB-118 is modified by substitution of a hydrogen atom for $-\mathrm{NO}_{2},-\mathrm{Br}$ and $-\mathrm{Cl}$.

In order to understand the nature of the electronic transitions responsible for the bands observed in the investigated systems, we carried out an analysis of the Kohn-Sham molecular orbitals in these transitions. Figure 14 shows the Kohn-Sham molecular orbitals involved in the electronic transitions in LQB-118.

According to Figure 14, the two absorption bands observed in LQB-118 are essentially characterized by electronic transition of the type $\pi-\pi^{*}$ and $n-\pi^{*}$. As can also be seen in Figure 14, the atoms of the quinone moiety contribute more effectively for the molecular orbitals related with the electronic transitions of the absorption bands at 265.0 and $330.0 \mathrm{~nm}$. On the other hand, as shown in Figure 15, the absorption bands at 284.0 and 314 nm calculated for LQB-149 are mostly characterized by electronic transitions involving molecular orbitals composed essentially by $\mathrm{NO}_{2}$-functionalized aromatic ring adjacent to the quinone moiety. The comparison of the Kohn-Sham molecular orbitals of LQB-118 and LQB-149 shows clearly how the substitution with $-\mathrm{NO}_{2}$ affects the electronic structure of LQB-118.

In order to provide additional support for the mechanism proposed in this paper for the reduction process of LQB-118, LQB-149, LQB-150 and LQB-151, we calculated at $\omega \mathrm{B} 97 \mathrm{DX} / \mathrm{TZVP}(\mathrm{LR}-\mathrm{PCM})$ level the UV-Vis 

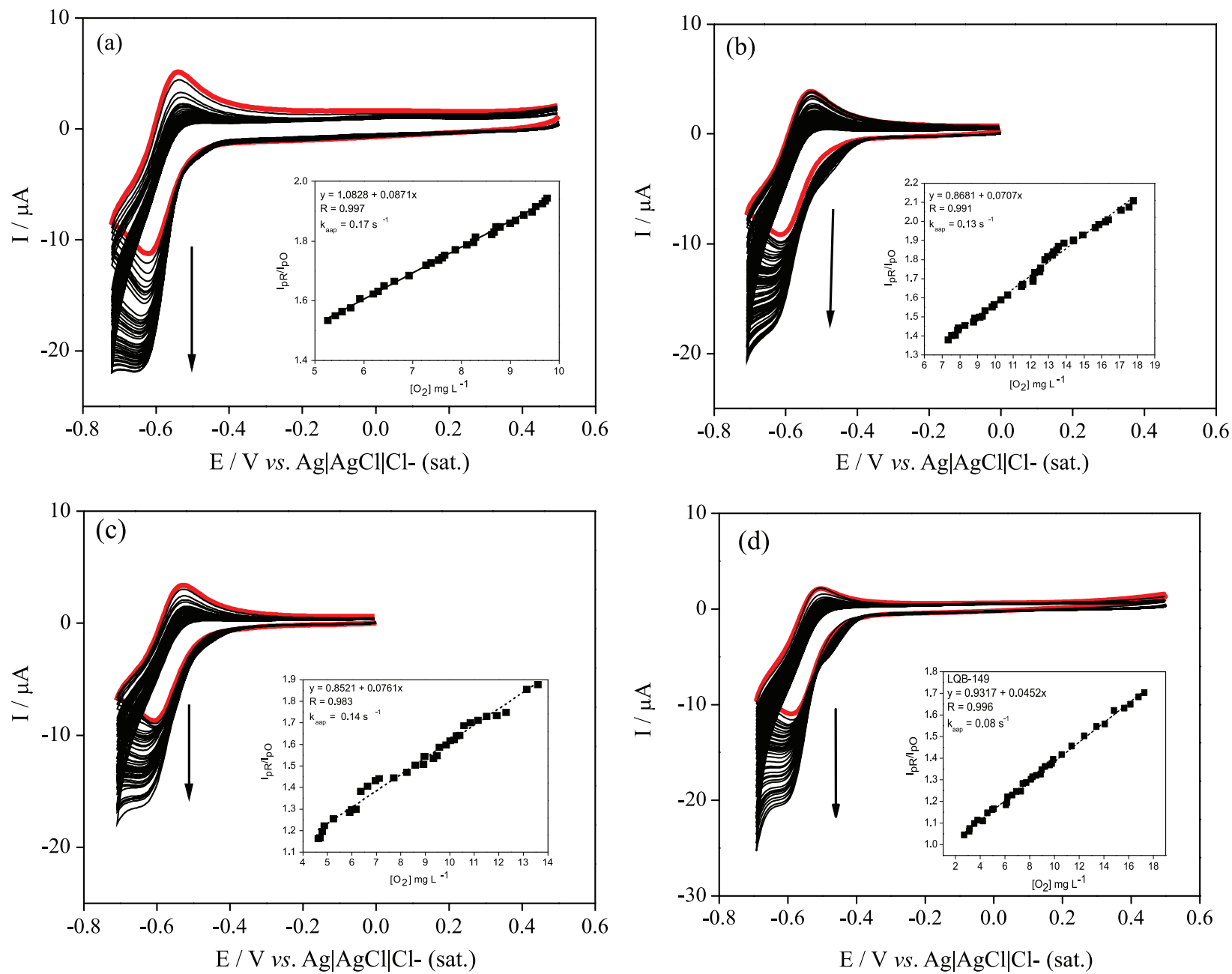

Figure 12. Cyclic voltammograms for the studied compounds in DMF + TBAP $\left(0.1 \mathrm{~mol} \mathrm{~L}^{-1}\right)$, GCE, in absence of oxygen (red) and in the presence of different concentrations of oxygen, $v=50 \mathrm{mV} \mathrm{s}^{-1}$. (a) LQB-118; (b) LQB-150; (c) LQB-151; (d) LQB-149. Insert: linear graphs of $\mathrm{Ip}_{\mathrm{R}} / \mathrm{Ip}_{\mathrm{O}}$ in function of oxygen concentration, to obtain the apparent constant of reactivity toward oxygen.

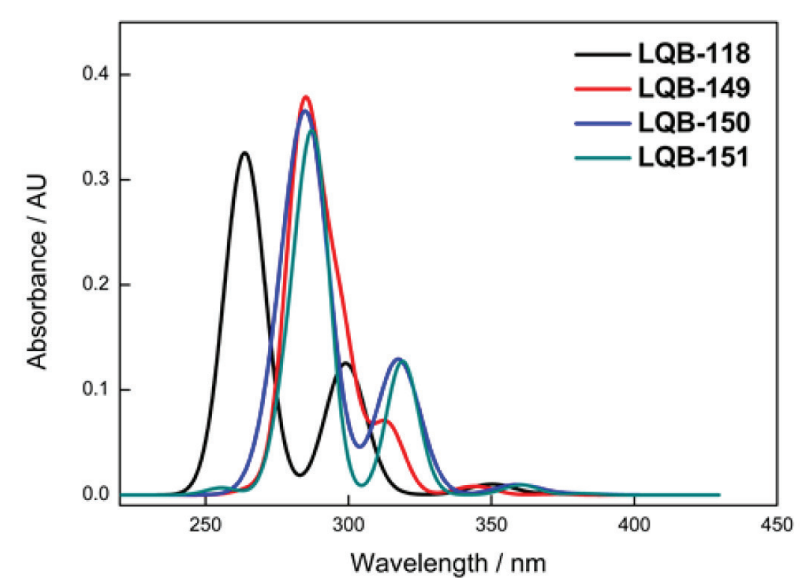

Figure 13. Electronic spectra calculated at $\omega \mathrm{B} 97 \mathrm{DX} / \mathrm{TZVP}(\mathrm{LR}-\mathrm{PCM})$ level for LQB-118, LQB-149, LQB-150 and LQB-151 molecules.

spectrum of the reduced form of these compounds generated via successive reduction steps and compared with experimental results. Figure 16 shows the calculated UV-Vis spectra of the LQB-118, LQB-149, LQB-150 and
LQB-151 and their reduced forms, IIIc, followed by the analysis of the Kohn-Sham molecular orbitals involved in the electronic transitions.

Analyzing the results presented in Figure 16, it is possible to note some relationship between theory and experiment. For instance, the spectroelectrochemical study revealed that the reduction process of LQB-149 molecule is characterized by the appearance of a new absorption band at $432 \mathrm{~nm}$. Our computational results, shown in Figure 16 (curve in red), predict the appearance of an intense band at around $406 \mathrm{~nm}$, whose Kohn-Sham molecular orbitals analysis (Figure 17) indicates to be related to an electronic transition involving essentially the quinone ring portion and the $\mathrm{NO}_{2}$-functionalized aromatic ring. The computational results of Figure 16 also show, as observed experimentally, that the UV-Vis spectrum profile of the reduced form of LQB-149 has a pattern different from the other pterocarpanquinones, herein investigated. 


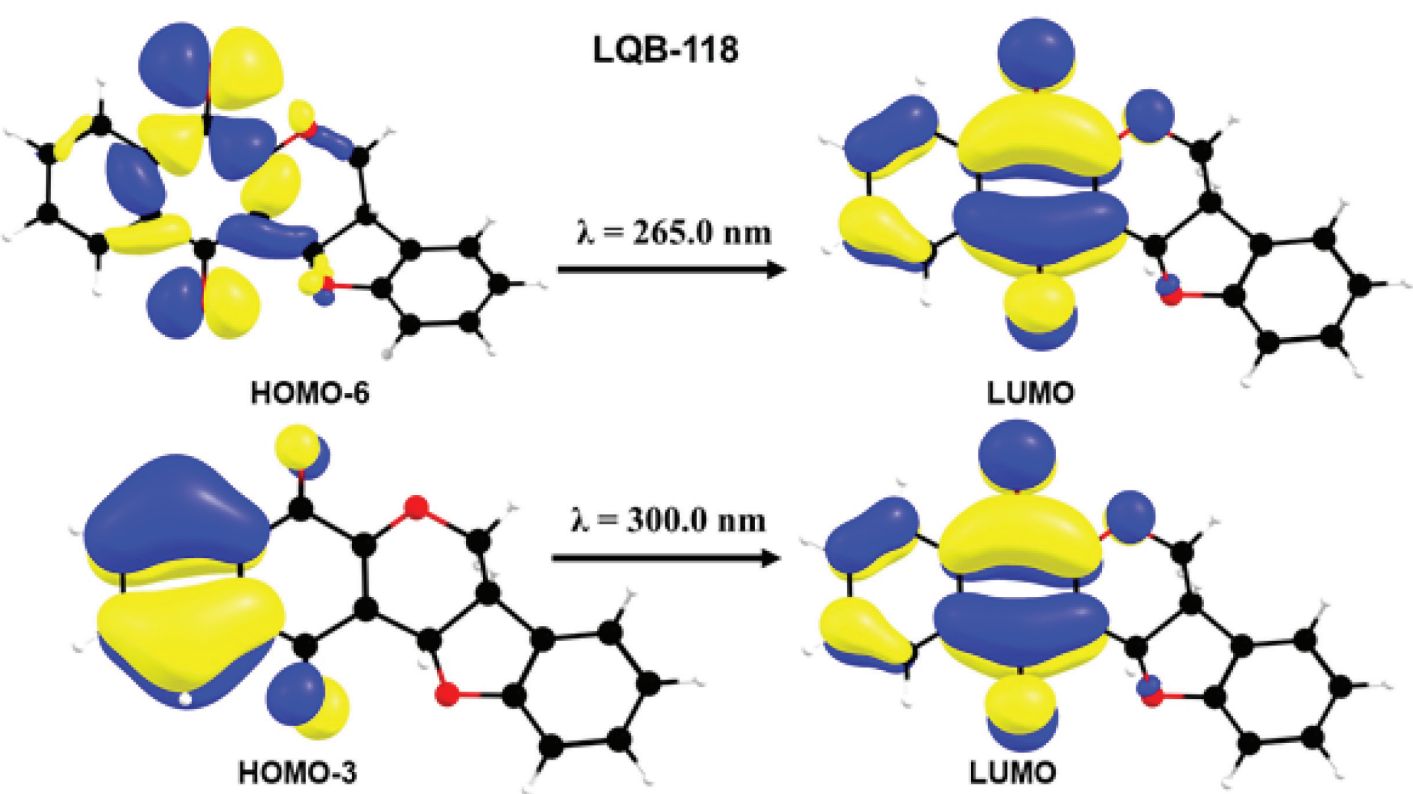

Figure 14. The Kohn-Sham molecular orbitals involved electronic transitions related with the absorption bands in LQB-118.

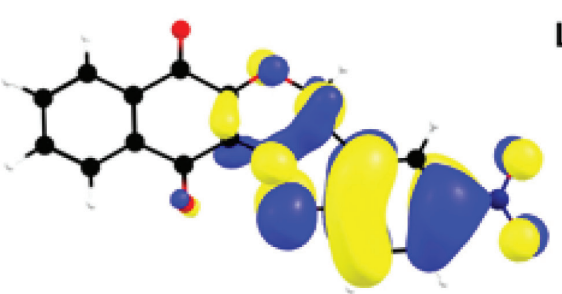

Hомо
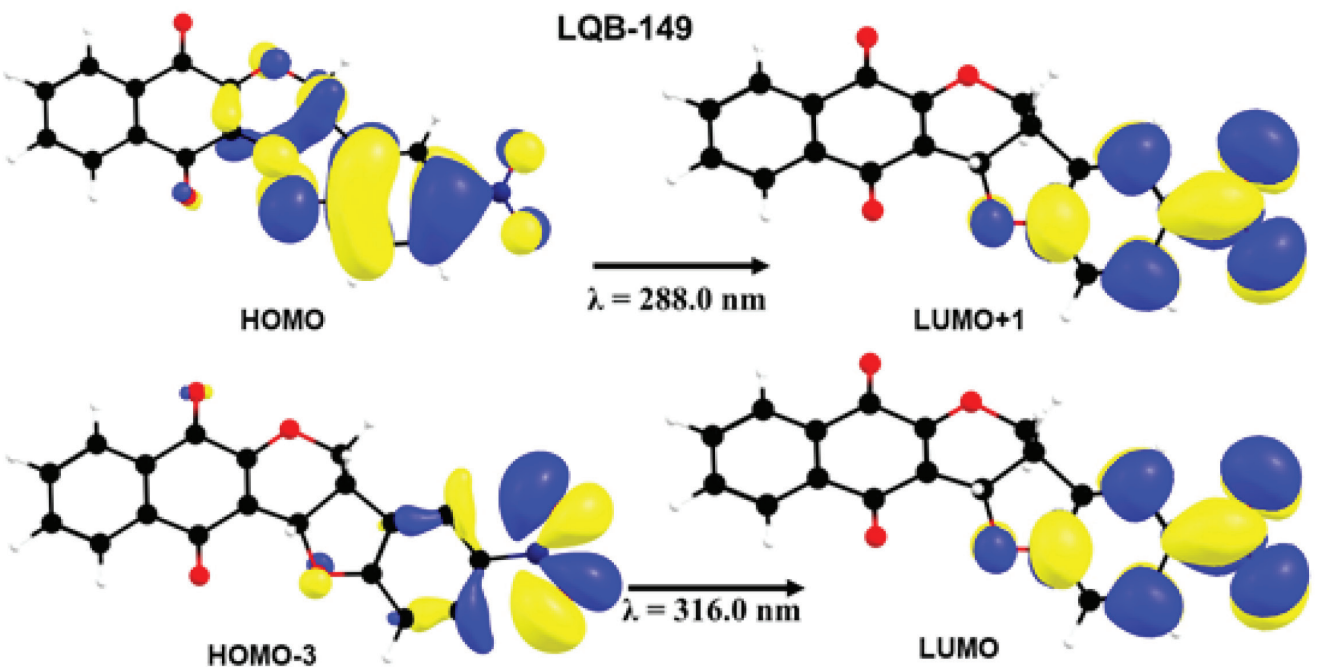

LUMO+1

Figure 15. The Kohn-Sham molecular orbitals involved electronic transitions related with the absorption bands in LQB-149 molecule.

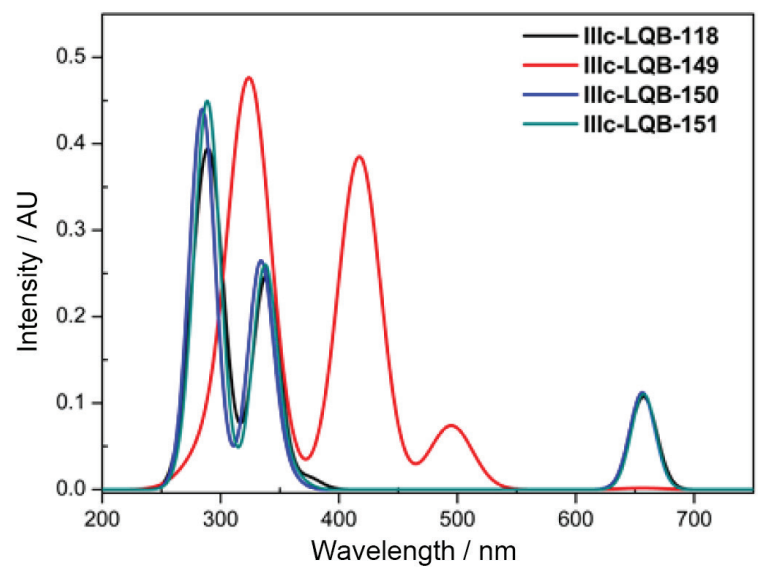

Figure 16. Electronic spectra calculated at $\omega B$ 97DX/TZVP(LR-PCM) level for reduced forms of the pterocarpanquinones studied.
Also, in line with part of experimental results, our computational results obtained at $\omega \mathrm{B} 97 \mathrm{DX} /$ TZVP(LR-PCM) level of theory, predict the appearance of a low intensity absorption band above $600.0 \mathrm{~nm}$ for reduced form of LQB-118, LQB-150 and LQB-151 compounds. Kohn-Sham molecular orbitals analysis shows that this absorption band is related with electronic transitions involving essentially the quinone portion of these molecules (Figure S1, SI section). It is worth noting that according to our theoretical results, the functionalization of aromatic ring in LQB-118 (curve in black), with the halogens $\mathrm{Cl}$ and $\mathrm{Br}$ (curves in blue and dark cyan) does not provide significant changes in the profile of their reduced form UV-Vis spectra. Similar 


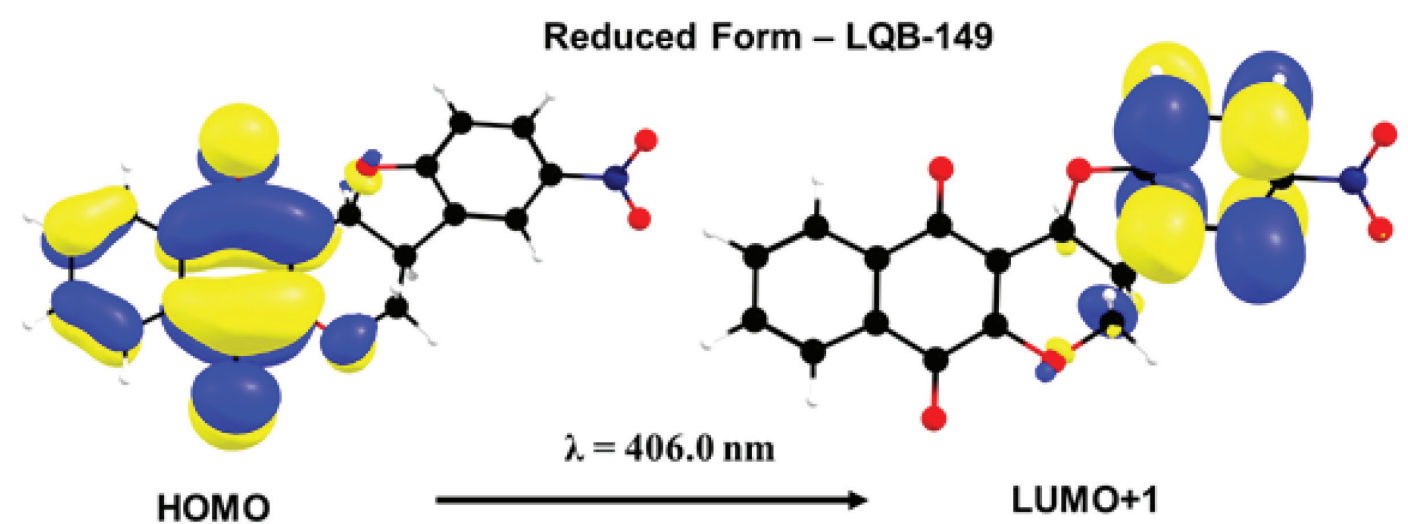

Figure 17. The Kohn-Sham molecular orbitals involved electronic transitions related with the absorption band at $400.0 \mathrm{~nm}$ in reduced form of LQB-149 molecule.

behavior was also observed experimentally. Nevertheless, contrary to what has been observed experimentally, our calculations do not reveal appearance of the absorption bands at 400 and $470 \mathrm{~nm}$ measured for reduced forms of LQB-118, LQB-150 and LQB-151. It is well known that the quality of DFT and TD-DFT results is quite dependent on factors as nature of the exchange-correlation functional and basis set, ${ }^{29}$ so that the establishment of an accurate methodology requires the performance of systematic studies. This type of analysis is not the main goal of the current work, and these referred issues will be evaluated in future work. In any case, the $\omega \mathrm{B} 97 \mathrm{DX} /$ TZVP(LR-PCM) results obtained here can be interpreted in a semi-quantitative way and have provided additional support for proposed mechanism for reduction of pterocarpanquinones.

\section{Conclusions}

The electrochemical results have confirmed the difference in behavior of the modified pterocarpanquinones: the halogenated ones follow the behavior of LQB-118, while the nitroderivative presents a reduction profile compatible with the generation, at the second reduction potential, of a dianion-diradical, which can explain, in part, its higher cytotoxicity towards normal cells, decreasing its selectivity index. However, this special feature allows LQB-149 to be an effective parasiticidal compound. We may affirm that electrochemical methods contribute significantly to the definition of the mechanism of molecular action of drugs, particularly when quinonemethides $(\mathrm{QM})$ are involved as electrogenerated intermediates or in the case of the release of reactive oxygen species (ROS), among other possibilities. Overall, electrochemical techniques appear well adapted to explore redox pathways in vitro, which can be related to in vivo studies.

\section{Supplementary Information}

Supplementary data (DFT and NMR) are available free of charge at http://jbcs.sbq.org.br as PDF file.

\section{Acknowledgments}

The authors wish to thank the Brazilian financial agencies: CNPq, CAPES, FAPEAL, FAPERJ and INCT in Bioanalytics (FAPESP grant No. 2014/50867-3 and CNPq grant No. 465389/2014-7, 458114/2014-6). The authors also thank the LQTC (Laboratório de Química Teórica e Computacional, Universidade Federal de Pernambuco) for the computational resources used to perform the calculations. They also acknowledge the excellent revision done by reviewers of the present manuscript.

\section{References}

1. Kumagai, Y.; Shinkai, Y.; Miura, T.; Cho, A. K.; Annu. Rev. Pharmacol. Toxicol. 2012, 52, 221; Colucci, M. A.; Moody, C. J.; Couch, G. D.; Org. Biomol. Chem. 2008, 6, 637; Ma, W.; Long, Y.-T.; Chem. Soc. Rev. 2014, 43, 30; Bolton, J. L.; Trush, M. A.; Penning, T. M.; Dryhurst, G.; Monks, T. J.; Chem. Res. Toxicol. 2000, 13, 135; Bolton, J. L.; Dunlap, T.; Chem. Res. Toxicol. 2017, 30, 13.

2. Hillard, E. A.; de Abreu, F. C.; Ferreira, D. C. M.; Jaouen, G.; Goulart, M. O. F.; Amatore, C.; Chem. Commun. 2008, 2612; Kovacic, P.; Somanathan, S.; Anti-Cancer Agents Med. Chem. 2011, 11, 658; Santini, C.; Pellei, M.; Gandin, V.; Porchia, M.; Tisato, F.; Marzano, C.; Chem. Rev. 2014, 114, 815.

3. Klotz, L.-O.; Hou, X.; Jacob, C.; Molecules 2014, 19, 14902.

4. Netto, C. D.; da Silva, A. J. M.; Salustiano, E. J. S.; Bacelar, T. S.; Riça, I. G.; Cavalcante, M. C. M.; Rumjanek, V. M.; Costa, P. R. R.; Bioorg. Med. Chem. 2010, 18, 1610.

5. Silva, T. L.; Ferreira, F. R.; Vasconcelos, C. C.; da Silva, R. C.; 
Lima, D. J. P.; Costa, P. R. R.; Netto, C. D.; Goulart, M. O. F.; ChemElectroChem 2016, 3, 2252.

6. Martino, T.; Kudrolli, T. A.; Kumar, B.; Salviano, I.; Mencalha, A.; Coelho, M. G. P.; Justo, G.; Costa, P. R. R.; Sabino, K. C. C.; Lupold, S. E.; Prostate 2018, 78, 140.

7. Silva, K. L.; Souza, P. S.; Costa, P. R. R.; Maia, R. C.; Clin. Cancer Res. 2015, 21, A51.

8. da Silva, L. L. R.; Portes, J. A.; de Araújo, M. H.; Silva, J. L. S.; Rennó, M. N.; Netto, C. D.; da Silva, A. J. M.; Costa, P. R. R.; de Souza, W.; Seabra, S. H.; DaMatta, R. A.; Parasitol. Int. 2015, 64, 622 .

9. Wondrak, G. T.; Antioxid. Redox Signaling 2009, 11, 3013; McKeown, S. R.; Coweny, R. L.; Williamsy, K. J.; Clin. Oncol. 2007, 19, 427; Rahman, M. H.; Bal, M. K.; Jones, A. M.; ChemElectroChem 2019, 6, DOI: 10.1002/celc.201900117.

10. Ribeiro, G. A.; Cunha-Junior, E. F.; Pinheiro, R. O.; da-Silva, S. A. G.; Canto-Cavalheiro, M. M.; da Silva, A. J. M.; Costa, P. R. R.; Netto, C. D.; Melo, R. C. N.; Almeida-Amaral, E. E.; Torres-Santos, E. C.; J. Antimicrob. Chemother. 2013, 68, 789.

11. Nepali, K.; Lee, H.-Y.; Liou, J.-P.; J. Med. Chem. 2019, 62, 2851; Hammerich, O. In Organic Electrochemistry; Hammerich, O.; Speiser, B., eds.; CRC Press: Boca Raton, 2016, p. 1149 (and included references).

12. Armendáriz-Vidales, G.; Hernández-Muñoz, L. S.; González, F. J.; de Souza, A. A.; de Abreu, F. C.; Jardim, G. A. M.; da Silva Júnior, E. N.; Goulart, M. O. F.; Frontana, C.; J. Org. Chem. 2014, 79, 5201.

13. Saveant, J. M.; Elements of Molecular and Biomolecular Electrochemistry: An Electrochemical Approach to Electron Transfer Chemistry; Wiley: New York, 2006; Andrieux, C. P.; Le Gorande, A.; Saveant, J. M.; J. Am. Chem. Soc. 1992, 114, 6892; Gennaro, A.; Isse, A. A.; Bianchi, C. L.; Mussini, P. R.; Rossi, M.; Electrochem. Commun. 2009, 11, 1932; Jardim, G. A. M.; Silva, T. L.; Goulart, M. O. F.; de Simone, C. A.; Barbosa, J. M. C.; Salomão, K.; de Castro, S. L.; Bower, J. F.; da Silva Júnior, E. N.; Eur. J. Med. Chem. 2017, 136, 406.

14. Ma, W.; Zhou, H.; Ying, Y.; Li, D.; Chen, G.; Long, Y.; Chen, H.; Tetrahedron 2011, 67, 5990; Costentin, C.; Chem. Rev. 2008, 108, 2145; Rapta, P.; Dmitrieva, E.; Alexey, A.; Popov, A. A.; Dunsch, L. In Organic Electrochemistry; Hammerich, O.; Speiser, B., eds.; CRC Press: Boca Raton, 2016, p. 169 (and included references).

15. de Moraes, P. F.; Gaspar, F. V.; Borges, R. H. F.; Netto, C. D.; Leão, R. A. C.; Nájera, C.; Costa, P. R. R.; Synthesis 2015, 47, 3505.

16. de Paiva, Y. G.; Silva, T. L.; Xavier, A. F. A.; Cardoso, M. F. C.; da Silva, F. C.; Silva, M. F. S.; Pinheiro, D. P.; Pessoa, C.; Ferreira, V. F.; Goulart, M. O. F.; J. Braz. Chem. Soc. 2019, 30, 658.
17. Becke, A. D.; J. Chem. Phys. 1993, 98, 5648.

18. Schaefer, A.; Huber, C.; Ahlrichs, R.; J. Chem. Phys. 1994, 100, 5829.

19. Chai, J.-D.; Head-Gordon, M.; Phys. Chem. Chem. Phys. 2008, 10,6615 .

20. Chai, J.-D.; Head-Gordon, M.; J. Chem. Phys. 2008, 128, 84106.

21. Tomasi, J.; Mennucci, B.; Cammi, R.; Chem. Rev. 2005, 105, 2999.

22. Frisch, M. J.; Trucks, G. W.; Schlegel, H. B.; Scuseria, G. R.; Robb, M. A.; Cheeseman, J. R.; Scalmani, G.; Barone, V.; Mennucci, B.; Petersson, G. A.; Nakatsuji, H.; Caricato, M.; Li, X.; Hratchian, H. P.; Izmaylov, A. F.; Blonio, J.; Zheg, G.; Sonnenberg, J. L.; Hada, M.; Ehara, M.; Toyota, K.; Fukuda, R.; Hasegawa, J.; Ishida, M.; Nakajima, T.; Honda, Y.; Kitao, O.; Nakai, H.; Vreven, T.; Montgomery, J. A.; Peralta, J. E.; Ogliaro, F.; Bearpark, M.; Heyd, J. J.; Brothers, E.; Kundin, K. N.; Staroverov, V. N.; Keith, T.; Kobayashi, R.; Normand, J.; Raghavachari, K.; Rendell, A.; Burant, J. C.; Iyengar, S. S.; Tomasi, J.; Cossi, M.; Rega, N.; Millam, J. M.; Klene, M.; Knox, J. E.; Cross, J. B.; Bakken, V.; Adamo, C.; Jaramillo, J.; Gomperts, R.; Stratmann, R. E.; Yazyev, O.; Austin, A. J.; Cammi, R.; Pomelli, C.; Ochterski, J. W.; Martin, R. L.; Morokuma, K.; Zakrzewski, V. G.; Voth, G. A.; Salvador, P.; Dannenberg, J. J.; Dapprich, S.; Daniels, A. D.; Farkas, O.; Foresman, J. B.; Ortiz, J. V.; Cioslowski, J.; Fox, D. J.; Gaussian09, Revision D.01; Gaussian, Inc., Wallingford, CT, 2013.

23. Song, Y.; Buettner, G. R.; Free Radical Biol. Med. 2010, 49, 919; Augusto, O.; Miyamoto, S. In Principles of Free Radical Biomedicine, vol. 1; Pantopoulos, K.; Schipper, H. M., eds.; Nova Science Publishers, Inc.: Hauppauge, NY, 2011, p. 19; Antunes, F.; Salvador, A.; Marinho, H. S.; Alves, R.; Pinto, R. E.; Free Radical Biol. Med. 1996, 21, 917; Nohl, H.; Jordan, W.; Bioorg. Chem. 1987, 15, 374.

24. Moore, H. W.; Czerniak, R.; Med. Res. Rev. 1981, 1, 249.

25. Barker, B.; Diao, L.; Wan, P. J.; J. Photochem. Photobiol., A 1997, 104, 91.

26. Skibo, E. B. In Quinone Methides, vol. 1; Rokita, S. E., ed.; Wiley: Hoboken, 2009, p. 217; Toteva, M.; Richard, J. P.; Adv. Phys. Org. Chem. 2011, 45, 39; Wellington, W.; RSC Adv. 2015, 5, 20309; Amouri, H.; Synlett 2011, 10, 1357.

27. Cao, S.; Peng, X.; Curr. Org. Chem. 2014, 18, 70.

28. Liška, A.; Rosenkranz, M.; Klíma, J.; Dunsch, L.; Lhoták, P.; Ludvík, J.; Electrochim. Acta 2014, 140, 572; Squella, J. A.; Bollo, S.; Nunez-Vergara, L. J.; Curr. Org. Chem. 2005, 9, 565.

29. Laurent, A. D.; Jacquemin, D.; Int. J. Quantum Chem. 2013, 11, 2019.

Submitted: March 19, 2019 Published online: July 16, 2019 